\title{
Hydrogen production during zinc deposition from alkaline zincate solutions
}

\author{
R. E. F. EINERHAND, W. H. M. VISSCHER, E. BARENDRECHT \\ Laboratory for Electrochemistry, Department of Chemical Technology, Eindhoven University of Technology, \\ P.O. Box 513, 5600 MB Eindhoven, The Netherlands
}

Received 13 March 1988; revised 16 May 1988

The determination of the amount of hydrogen produced during the electrodeposition of zinc from alkaline zincate solutions was carried out using the rotating ring-disc electrode (RRDE) technique. The experimental conditions for which the RRDE technique offers reliable results are discussed. Hydrogen production during zinc deposition was studied for a range of cathodic (disc) current densities (20-500 $\mathrm{A} \mathrm{m}^{-2}$ ) and electrolyte compositions (1-7 M KOH, 0.01-0.2 M zincate). It was found that an increasing amount of hydrogen was formed with increasing (disc) current density and decreasing $\mathrm{KOH}$ and zincate concentration. The impact of hydrogen formation during the charging process on nickel oxide/zine secondary battery performance is expected to be small. It is concluded that in battery electrolytes ( $8 \mathrm{M} \mathrm{KOH}, 1 \mathrm{M}$ zincate) hydrogen is formed chiefly by corrosion of the zinc electrode rather than by electrochemical formation during the electrochemical reduction of zinc.

\section{Introduction}

The charging process of alkaline zinc secondary batteries is accompanied by the formation of hydrogen. The current and coulombic efficiency and, partly, the energy efficiency of the charging process, are dictated by the production of hydrogen. The amount of hydrogen produced depends in turn on experimental conditions such as electrolyte and battery plate composition, current density and temperature.

The deposition process of zinc from acidic electrolytes has been extensively studied because of the economic interest of the process. In recent works reporting on this process [1-5], high purity synthetic electrolytes are considered and the impact of various impurities on current efficiency $[1,2]$ and deposit morphology $[4,5]$ are discussed. Literature on the electrowinning of zinc from alkaline solutions is sparse since application of this process is still limited. St Pierre and Piron [6] studied the electrodeposition of zinc from alkaline zincate $(0.92 \mathrm{M} \mathrm{ZnO})$ solutions with copper and arsenide impurities. They found a $100 \%$ current efficiency for $\mathrm{NaOH}$ concentrations in the range of $7.5-12.5 \mathrm{M}$, current densities from 50 to $1000 \mathrm{~A} \mathrm{~m}^{-2}$ and temperatures rising from 24 to $74^{\circ} \mathrm{C}$ in the presence of copper but not with arsenide. The appearance of the deposit is only affected by the presence of arsenide impurity. St Pierre and Piron also found that zinc electrowinning from alkaline zincate is more efficient and less affected by impurities in the electrolyte than from acidic sulphate solutions. In a recent review on zinc plating from alkaline zincate solutions [7], Wilcox and Mitchell contradict these results, and consider the alkaline bath to be less efficient than the acidic bath. However, the alkaline zincate baths have proved promising as an alternative for cyanide-based plating solutions.

Rogers and Taylor [8] studied zinc electrodeposition from alkaline zincate electrolytes $(0.01-0.3 \mathrm{M}$ zincate, $3 \mathrm{M} \mathrm{KOH})$ with the rotating disc electrode and established separate zinc deposition and hydrogen evolution current density versus potential curves. They concluded that the zinc reduction reaction is always mass transport limited and, consequently, dendritic deposits are obtained. Since these dendrites are high current density sites on the electrode, hydrogen formation will take place mainly at these dendrites. Mass transport enhancement as a result of hydrogen formation will be more efficient at high current densities, where dendritic nucleation is favoured rather than dendritic growth, thus creating a stable planar high surface area. Therefore, Rogers and Taylor conclude that some hydrogen production may be beneficial during the charging of the zinc secondary battery.

Zinc electrode corrosion has been studied by several authors. Snyder and Lander [9] investigated the selfdischarge rate of zinc battery electrodes as a function of $\mathrm{KOH}$ and zincate concentration and amalgamation level of the electrode. They found a decrease of hydrogen production with increasing $\mathrm{KOH}$ concentration and with increasing mercury content of the electrode. Dirkse and Timmer [10] obtained similar results for zincate-free alkaline media. In zincatesaturated alkaline solutions zinc electrode corrosion was found to decrease significantly. In contrast with their results in pure $\mathrm{KOH}$ solutions an increase of zinc corrosion was observed with increasing $\mathrm{KOH}$ concentration in the presence of zincate ions, in agreement with the findings of Muralidharan and Rajagopalan [11].

Various methods for the determination of hydrogen 
have been developed in the past. However, the most commonly used techniques are less applicable when very small amounts of hydrogen have to be determined; for example, the measurement of the total volume of $\mathrm{H}_{2}[9,10]$ is impossible, because the hydrogen solubility in alkaline zincate electrolytes is unknown. Also, the determination of the total weight of the zinc deposit and the electrochemical stripping of zinc $[1,2,4,8]$ are only accurate when the zinc deposit is adherent and the corrosion of zinc is negligible.

The rotating ring-disc electrode (RRDE) technique is a fast and reliable method which can detect small amounts of hydrogen and has been used for the estimation of the coulombic efficiency of zinc electrodeposition from an acidic sulphate bath by Frazer and Hamilton [3].

This work reports on the production of hydrogen during the deposition of zinc from aqueous alkaline zincate solutions, using the RRDE technique. The amount of hydrogen was determined for various current densities and potassium hydroxide and zincate concentrations. An analysis of the applicability of this method is presented.

\section{Experimental details}

A standard three-compartment electrochemical cell with an $\mathrm{Hg} / \mathrm{HgO}$ reference and a platinum counter electrode was used. The electrochemical measurements were made with a Tacussel bipotentiostat (Bi-Pad) and a Hewlett Packard HP 7046A XY recorder. A detailed description of the rotating ringdisc assembly is given elsewhere [12].

The Pt/Au RRDE $\left(r_{1}=4.01, r_{2}=4.40, r_{3}=\right.$ $4.91 \mathrm{~mm}$; disc area $=50.6 \mathrm{~mm}^{2}$ ) was polished with $0.05 \mu \mathrm{m} \mathrm{Al}_{2} \mathrm{O}_{3}$. The platinum ring was platinized and the collection efficiency determined experimentally, using a freshly prepared solution of ferricyanide/ ferrocyanide in $1 \mathrm{M} \mathrm{KOH}$. The experimental collection efficiency was in good agreement with the calculated value, interpolated from the data of Albery and Bruckenstein [13], viz. both 0.24 .

The measurements of the hydrogen production during the deposition of zinc were made following a strict procedure. First of all the collection efficiency of the $\mathrm{Pt} / \mathrm{Au}$ RRDE was determined for the production of hydrogen at the gold disc in zincate-free argonsaturated $\mathrm{KOH}$ solutions. It was calculated from the formula

$$
N=I_{\mathrm{R}} / I_{\mathrm{D}}
$$

where $N$ is the collection efficiency, $I_{\mathrm{R}}$ the hydrogen oxidation current at the ring and $I_{\mathrm{D}}$ the galvanostatic hydrogen formation current at the disc. The ring potential, $E_{\mathrm{R}}$, was set at $-0.2 \mathrm{~V}$ vs $\mathrm{Hg} / \mathrm{HgO}$, which is well within the mass transport region for the oxidation of dissolved hydrogen. Then, the gold disc was electroplated with a zinc layer $(3 \mu \mathrm{m})$ from an alkaline zinc bath, containing no additives. A series of measurements were started at least $30 \mathrm{~min}$ after the electrode had been transferred to the cell. During this time,

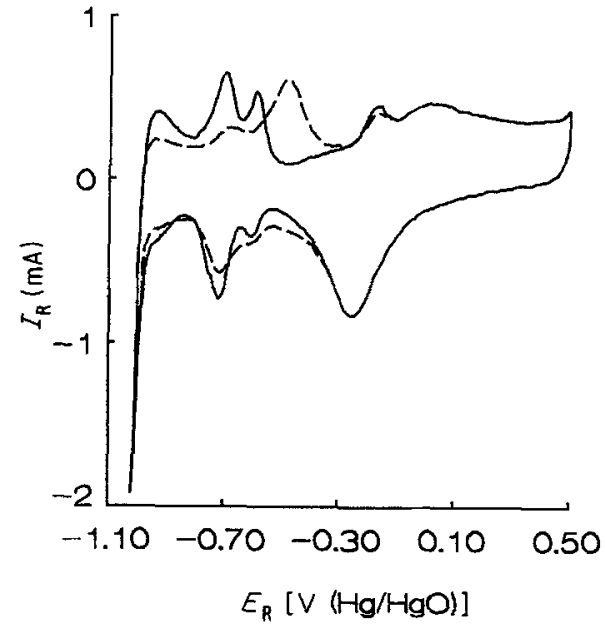

Fig. 1. Cyclic voltammogram at a platinum ring of a RRDE in an argon-saturated solution of pure $7 \mathrm{M} \mathrm{KOH}$ (solid line) and $7 \mathrm{M}$ $\mathrm{KOH}$ with $0.01 \mathrm{M}$ zincate (broken line). Scan rate $=0.1 \mathrm{~V} \mathrm{~s}^{-1}$, $f=25 \mathrm{~s}^{-1}$.

argon was bubbled through the solution to remove oxygen. The hydrogen production during the deposition of zinc was measured as a function of current density $\left(20-500 \mathrm{~A} \mathrm{~m}^{-2}\right)$ in an argon-saturated alkaline zincate electrolyte. The galvanostatic cathodic current was applied for $2 \mathrm{~min}$ irrespective of the current density used. A longer duration of the current 'pulse' can cause zincate depletion and hydrogen saturation of the electrolyte and eventually even unacceptable ringdisc gap narrowing. The current pulse was followed by at least 2 min with no current at the disc. The collection efficiency was again determined at the end of each series of measurements after the zinc deposit had been removed.

All experiments were performed at room temperature. The electrolytes were made from Analar grade potassium hydroxide and zinc oxide and doubly distilled water. The concentrations of the solute species are based on the assumption that zinc oxide is quantitatively converted to $\mathrm{Zn}(\mathrm{OH})_{4}^{2-}$, according to the equation

$$
\mathrm{ZnO}+\mathrm{H}_{2} \mathrm{O}+2 \mathrm{OH}^{-} \rightleftharpoons \mathrm{Zn}(\mathrm{OH})_{4}^{2-}
$$

\section{Results and discussion}

\subsection{The hydrogen oxidation reaction at platinum}

It is known that the presence of zinc ions in solution changes the behaviour of the platinum electrode. Therefore, first the oxidation of hydrogen at a platinum electrode was studied in alkaline zincate solutions. In Fig. 1, a voltammogram is shown of a platinum electrode in an argon-saturated $7 \mathrm{M} \mathrm{KOH}$ electrolyte with and without zincate ions. The addition of zincate ions alters the voltammogram in the low potential region, where zinc is adsorbed onto the platinum electrode. The oxidation current decreases significantly, which indicates that the hydrogen adsorption at the platinum surface is inhibited in zincate-containing electrolytes. 


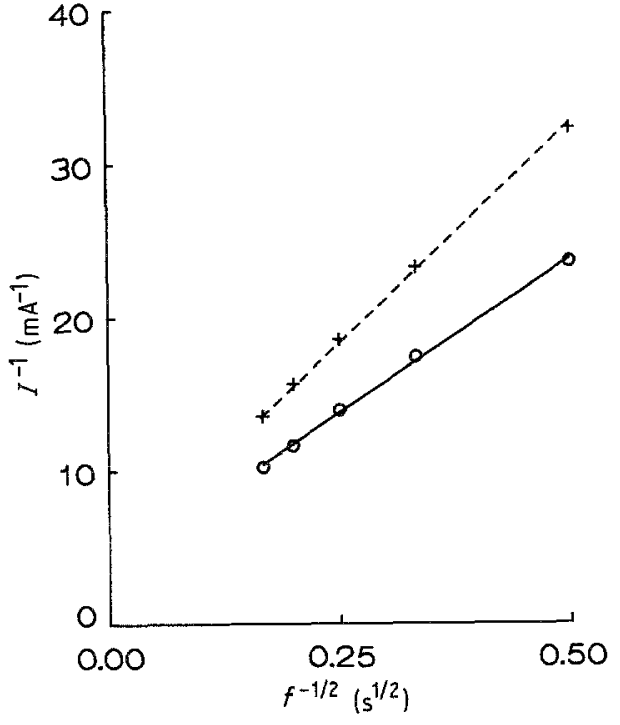

Fig. 2. The reciprocal limiting current for hydrogen oxidation at the platinum ring an RRDE in a hydrogen-saturated $7 \mathrm{M} \mathrm{KOH}$ solution, zincate free (solid line) and with $0.1 \mathrm{M}$ zincate (broken line), as a function $f^{-1 / 2} \cdot E_{\mathrm{R}}=-0.2 \mathrm{~V}(\mathrm{Hg} / \mathrm{HgO})$.

The oxidation of dissolved hydrogen was observed to be mass transport limited at potentials more anodic than the adsorption potential of zinc. This is depicted in Fig. 2, which presents the curve of the reciprocal limiting current versus the inverse square root of the rotation frequency at the ring electrode of an RRDE for the oxidation of dissolved hydrogen in a hydrogensaturated $7 \mathrm{M} \mathrm{KOH}$ solution with and without zincate, at a potential of $-0.2 \mathrm{~V}(\mathrm{Hg} / \mathrm{HgO})$. Similar plots were obtained when the potential of the Pt ring electrode was set at -0.25 and $-0.15 \mathrm{~V}$.

\subsection{The RRDE collection efficiency}

The collection efficiency was determined from measurements with hydrogen produced at the disc in argon-saturated zincate-free $\mathrm{KOH}$ solutions and was calculated using Equation 1. Preliminary experiments showed that freshly prepared platinized platinum deactivates slightly; this is attributable to textural changes of the platinized surface. A constant, though somewhat smaller value of the collection efficiency was observed, when the experiments were performed with an 'aged' platinized platinum ring which was treated in $1 \mathrm{M} \mathrm{H}_{2} \mathrm{SO}_{4}$ and $1 \mathrm{M} \mathrm{KOH}$ electrolytes before a series of measurements.

The experimental values of the collection efficiency as a function of disc current are presented in Fig. 3 for various $\mathrm{KOH}$ concentrations. The collection efficiency is constant for low disc currents but decreases for higher disc currents, which is attributed to the formation of hydrogen gas bubbles. The contribution of these bubbles to the measured ring current is less than that of dissolved $\mathrm{H}_{2}$ because only dissolved hydrogen can be directly oxidized at the platinum ring and because the transport of $\mathrm{H}_{2}$ in these bubbles from the disc to the ring has to occur through diffusion rather than by hydrodynamic flow which is slow, even for small bubbles. The presence of hydrogen bubbles at

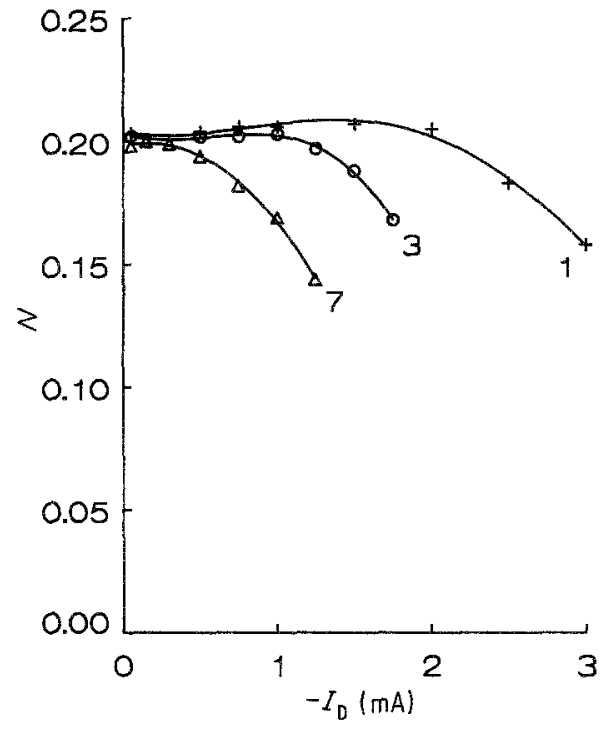

Fig. 3. The collection efficiency at the Pt/Au RRDE for hydrogen oxidation as a function of disc current. Numbers in figure indicate $c_{\mathrm{KOH}}(\mathrm{M}) \cdot E_{\mathrm{R}}=-0.2 \mathrm{~V}(\mathrm{Hg} / \mathrm{HgO}), f=25 \mathrm{~s}^{-1}$.

the electrode surface also causes mass transport enhancement and inhomogeneity of the current density distribution. Therefore, if the hydrogen solubility value is exceeded and $\mathrm{H}_{2}$ bubbles are formed, the collection efficiency decreases and the RRDE technique cannot be employed.

\subsection{The deposition of zinc}

A voltammogram for the electrodeposition of zinc onto the gold disc of a Pt/Au RRDE from an argonsaturated $0.05 \mathrm{M}$ zincate, $3 \mathrm{M} \mathrm{KOH}$ solution, is given in Fig. 4. The disc potential was scanned between -0.5 and $-1.6 \mathrm{~V}(\mathrm{Hg} / \mathrm{HgO})$, while the potential of the ring was kept at a constant value of $-0.2 \mathrm{~V}$. The deposition of zinc onto the gold substrate begins at about $-1.35 \mathrm{~V}$. The increase of the ring current before the electrodeposition of zinc at the gold disc occurs is due to hydrogen evolution. As soon as a zinc monolayer is formed on the gold disc the ring current first decreases slightly, but then increases again at more cathodic disc potentials. During the anodic sweep the disc current shows a peak due to the dissolution of zinc. Then, at the end of this peak of the disc current, the ring current also shows a peak due to the sudden onset of hydrogen evolution at the exposed gold substrate.

\subsection{The production of hydrogen during the deposition of zinc}

Hydrogen production during the deposition of zinc onto the zinc-plated gold disc was measured in $1-7 \mathrm{M} \mathrm{KOH}$ and $0.01-0.2 \mathrm{M}$ zincate electrolytes. Figure 5 shows the applied disc current, $I_{\mathrm{D}}$, and the measured ring current, $I_{\mathrm{R}}$, versus time, for an experiment in a $1 \mathrm{M} \mathrm{KOH}, 0.05 \mathrm{M}$ zincate solution. It is observed that the ring current is non-zero when the disc current is switched off. This ring current, 


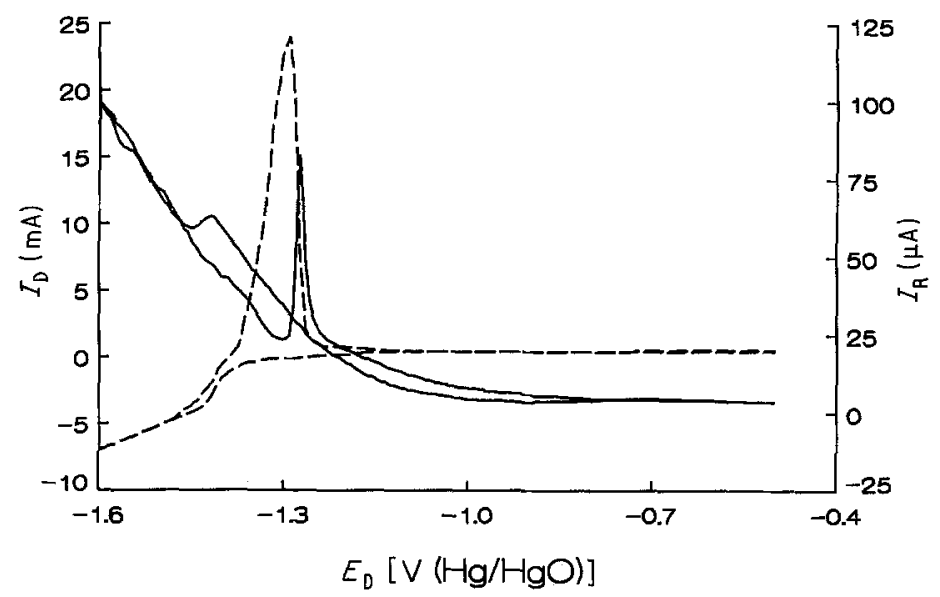

Fig. 4. Cyclic voltammogram at the gold disc of a Pt/Au RRDE, of an argon-saturated $3 \mathrm{M} \mathrm{KOH}, 0.05 \mathrm{M}$ zincate electrolyte; disc current (broken line), ring current (solid line). $E_{\mathrm{R}}=-0.2 \mathrm{~V}(\mathrm{Hg} / \mathrm{HgO}), f=25 \mathrm{~s}^{-1}$, scan rate $=0.1 \mathrm{~V} \mathrm{~s}^{-1}$.

$I_{\mathrm{R}}\left(I_{\mathrm{D}}=0\right)$, results from the oxidation of dissolved hydrogen produced during cathodic polarization in previous experiments and from hydrogen produced by corrosion of zinc.

Therefore, the ring current has to be corrected to obtain the actual amount of hydrogen produced at the disc during the deposition of zinc. The hydrogen current, $I_{\mathrm{H}_{2}}$, is a measure of the fraction of the applied disc current used for the production of hydrogen and is calculated from the formula

$$
I_{\mathrm{H}_{2}}=\left[I_{\mathrm{R}}-I_{\mathrm{R}}\left(I_{\mathrm{D}}=0\right)\right] / N
$$

where $I_{\mathrm{R}}$ is the measured ring current at the end of the 2-min cathodic polarization of the disc, $I_{\mathrm{R}}\left(I_{\mathrm{D}}=0\right)$ is the ring current at the end of the 2 -min period with zero disc current and $N$ is the average value of the collection efficiency, measured before and after each series of experiments.

In Figs 6, 7 and 8, the results of the hydrogen current measurements are presented as a function of disc current for various zincate and $\mathrm{KOH}$ concentrations. The plots show that $I_{\mathrm{H}_{2}}$ increases with increasing disc current. For low zincate concentrations $I_{\mathrm{H}_{2}}$ increases markedly with increasing disc current, whereas for higher zincate concentrations the increase of $I_{\mathrm{H}_{2}}$ becomes smaller and smaller.
The decrease of $I_{\mathrm{H}_{2}}$ with increasing zincate concentration and increasing $\mathrm{KOH}$ concentration is summarized in Figs 9 and 10, respectively. The decrease of $I_{\mathrm{H}_{2}}$ with increasing $c_{\mathrm{K}_{2} \mathrm{Zn}(\mathrm{OH})_{4}}$ is expected, since its limiting current increases when zincate concentration increases. The zinc equilibrium potential shifts to less negative values with increasing zincate concentration, hence the hydrogen production decreases at the same current density.

The relation between $I_{\mathrm{H}_{2}}$ and $c_{\mathrm{KOH}}$ is less clear. The decrease of $I_{\mathrm{H}_{2}}$ with increasing $c_{\mathrm{KOH}}$ cannot be the result of the change of the water and zinc reduction equilibrium potentials. The potential of both reactions shifts to more negative values but the shift of the water reduction potential is smaller than that for the zincate reduction reaction. Assuming that the kinetics of both reactions are unaltered, relatively more hydrogen should be formed at higher $\mathrm{KOH}$ concentrations and that is not the case.

The kinetics of one or both reactions can be affected by the $\mathrm{KOH}$ concentration. In pure $\mathrm{KOH}$ solutions, the hydrogen production at a zinc electrode was found to increase with increasing $\mathrm{KOH}$ concentration [11, 14-16], except for concentrations higher than $10 \mathrm{M} \mathrm{KOH} \mathrm{[15].} \mathrm{Several} \mathrm{mechanisms} \mathrm{for} \mathrm{the} \mathrm{hydrogen}$ evolution at a zinc electrode have been reported.

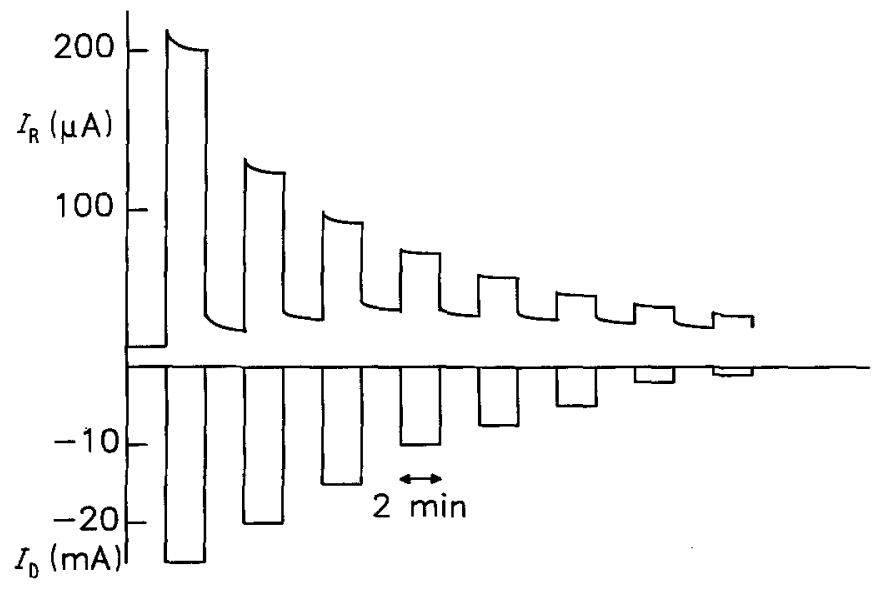

Fig. 5. The measured ring current versus time for various disc currents, in an argon-saturated $1 \mathrm{M} \mathrm{KOH}, 0.05 \mathrm{M}$ zincate electrolyte. $E_{\mathrm{R}}=-0.2 \mathrm{~V}(\mathrm{Hg} / \mathrm{HgO}), f=25 \mathrm{~s}^{-1}$. 


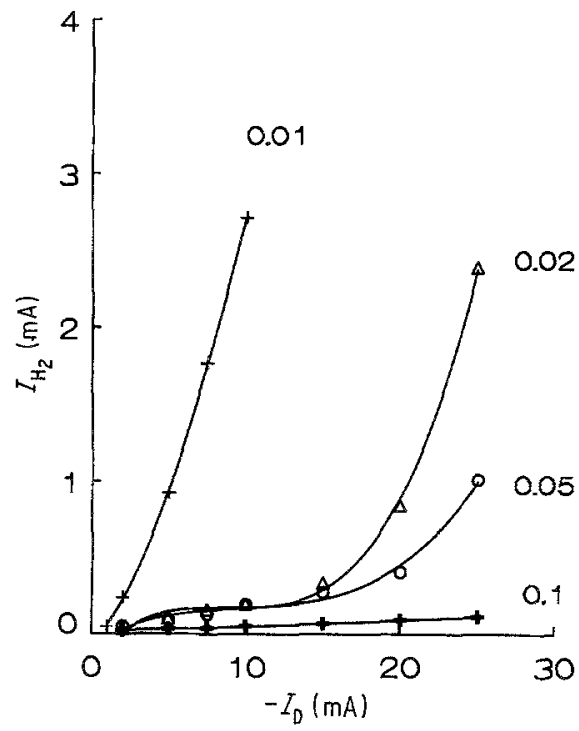

Fig. 6. The hydrogen current as a function of disc current for a $1 \mathrm{M}$ $\mathrm{KOH}$ electrolyte and various zincate concentrations. Numbers in figure indicate $c_{\left.\mathrm{K}_{2} \mathrm{ZniOH}\right)_{4}}(\mathrm{M}) . E_{\mathrm{R}}=-0.2 \mathrm{~V}(\mathrm{Hg} / \mathrm{HgO}), f=25 \mathrm{~s}^{-1}$.

At cathodic polarizations the proposed mechanism is $[11,14]$

$$
\begin{gathered}
\mathrm{Zn}+\mathrm{K}^{+}+e^{-} \rightleftharpoons \mathrm{K}(\mathrm{Zn}) \quad \text { (r.d.s.) } \\
\mathrm{K}(\mathrm{Zn})+\mathrm{H}_{2} \mathrm{O} \rightleftharpoons \mathrm{K}^{+}+\mathrm{Zn}+\mathrm{H}_{\text {ads }}+\mathrm{OH}^{-} \\
2 \mathrm{H}_{\mathrm{ads}} \rightleftharpoons \mathrm{H}_{2}
\end{gathered}
$$

Reaction 4 is the rate determining step. Since this step is dependent on potential and potassium ion concentration, it is expected that the hydrogen formation increases with increasing $\mathrm{KOH}$ concentration. In concentrated alkaline media $(>10 \mathrm{M} \mathrm{KOH})$ Iofa et al. [15] found that hydrogen production decreases with increasing $\mathrm{KOH}$ concentration. This can be ascribed to the decrease of the rate of Reaction 5 with $\mathrm{KOH}$ concentration, since the water concentration decreases. Thus, at high $\mathrm{KOH}$ concentrations, Reac-

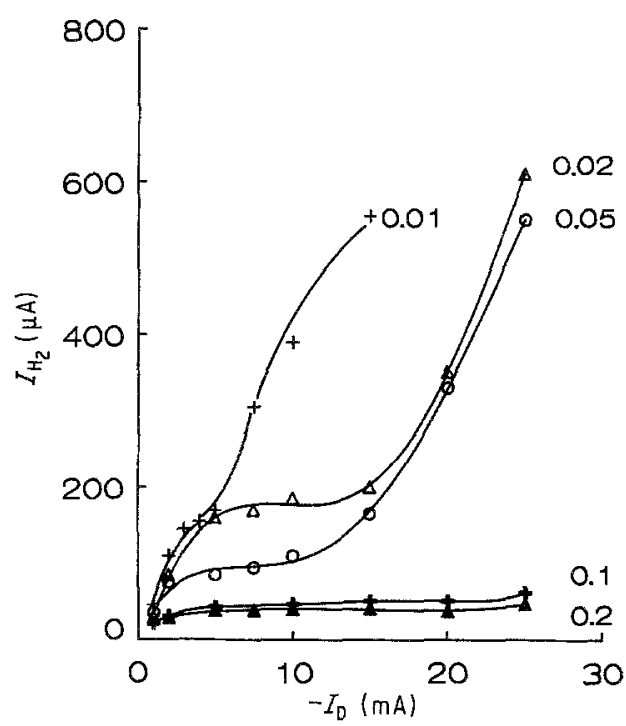

Fig. 7. The hydrogen current as a function of disc current for a $3 \mathrm{M}$

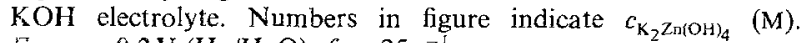
$E_{\mathrm{R}}=-0.2 \mathrm{~V}(\mathrm{Hg} / \mathrm{HgO}), f=25 \mathrm{~s}^{-1}$

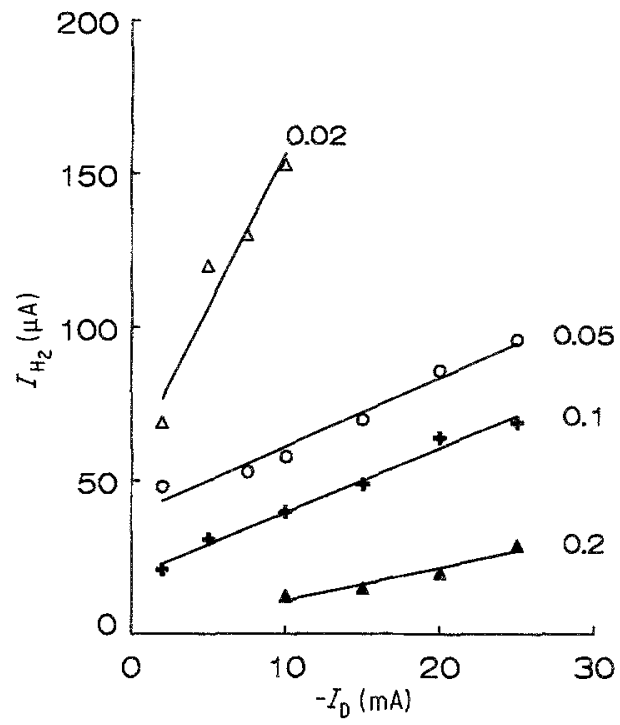

Fig. 8. The hydrogen current as a function of disc current for a $7 \mathrm{M}$ $\mathrm{KOH}$ electrolyte. Numbers in figure indicate $c_{\mathrm{K}_{2} \mathrm{Zn}(\mathrm{OH})_{4}}(\mathrm{M})$. $E_{\mathrm{R}}=-0.2 \mathrm{~V}(\mathrm{Hg} / \mathrm{HgO}), f=25 \mathrm{~s}^{-1}$

tion 5 becomes rate controlling, leading to a decrease of the hydrogen production with increasing $\mathrm{KOH}$ concentration.

The presence of zincate ions in solution can affect this mechanism and can even lead to an alternative route along which the $\mathrm{K}(\mathrm{Zn})$ species is discharged. As an example we suggest Reaction 7

$$
\begin{aligned}
\mathrm{K}(\mathrm{Zn}) & +\mathrm{Zn}(\mathrm{OH})_{4}^{2-} \rightleftharpoons \mathrm{K}^{+}+\mathrm{Zn} \\
& +\left[\mathrm{Zn}(\mathrm{OH})_{3}^{2-}\right]_{\text {ads }}+\mathrm{OH}^{-}
\end{aligned}
$$

This implies that $\mathrm{K}(\mathrm{Zn})$ can be discharged via Reaction 5 and/or Reaction 7. It is clear that if Reaction 7 takes place, the hydrogen production slows down in favour of zinc electrodeposition with increasing zincate concentration. Also, with increasing K.OH concentration the formation of the $\mathrm{K}(\mathrm{Zn})$ species increases, whereas the discharge of this species via

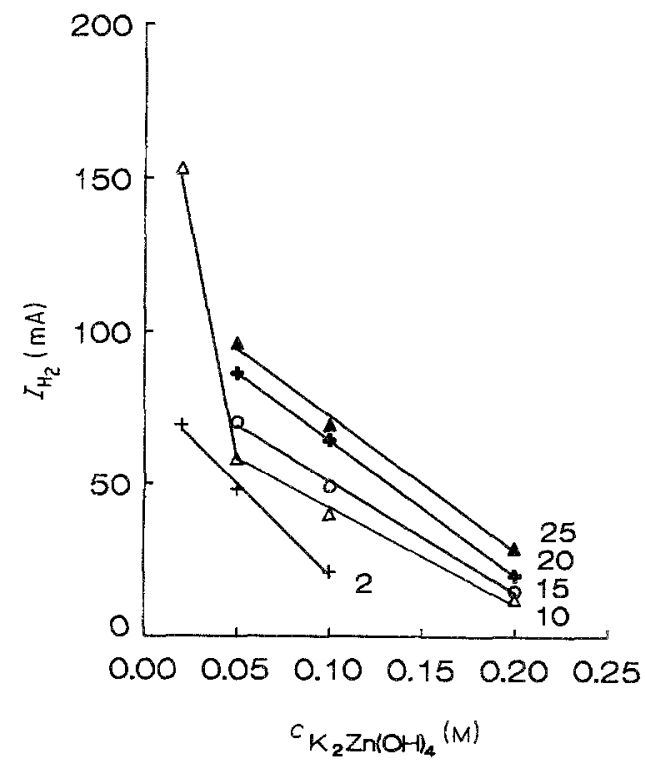

Fig. 9. The hydrogen current as a function of zincate concentration. Numbers in figure indicate applied disc current $(\mathrm{mA})$ $E_{\mathrm{R}}=-0.2 \mathrm{~V}(\mathrm{Hg} / \mathrm{HgO}), f=25 \mathrm{~s}^{-1}, c_{\mathrm{KOH}}=7 \mathrm{M}$. 


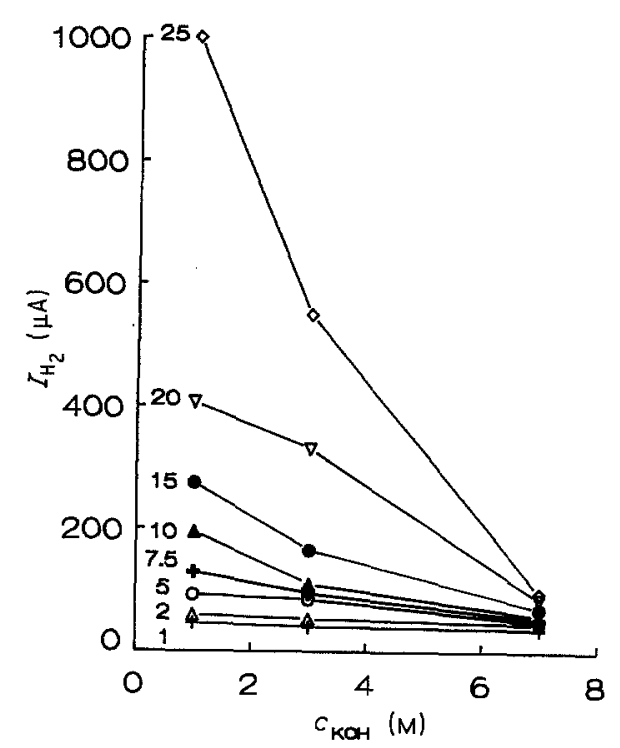

Fig. 10. The hydrogen current as a function of $\mathrm{KOH}$ concentration. Numbers in figure indicate applied disc current (mA). $E_{\mathrm{R}}=-0.2 \mathrm{~V}(\mathrm{Hg} / \mathrm{HgO}), f=25 \mathrm{~s}^{-1}, c_{\mathrm{K}_{2} \mathrm{Zn}(\mathrm{OH})_{4}}=0.05 \mathrm{M}$.

water reduction decreases. Hence, Reaction 7 becomes more important at higher $\mathrm{KOH}$ concentrations, resulting in a decrease of the hydrogen production with increasing $\mathrm{KOH}$ concentration.

The decrease of the hydrogen production with increasing $c_{\mathrm{KOH}}$ can also be ascribed to the preferential adsorption of the hydroxyl ion, which competes with the adsorption of hydrogen atoms at the zinc electrode surface, or to the increasing screening effect of the water molecules by the potassium ion in the double layer [15]. None of these models or the model proposed in the above section can be supported with irrefutable evidence. However, our model accounts for the increase of the hydrogen production during the deposition of zinc with increasing applied disc current density and decreasing zincate and $\mathrm{KOH}$ concentration, which is not the case with the other models.

\subsection{The corrosion of zinc}

It was pointed out earlier that at zero disc current a non-zero ring current is measured, $I_{\mathrm{R}}\left(I_{\mathrm{D}}=0\right)$. This oxidation current is due to dissolved hydrogen as a result of previous disc current pulses, $I_{R}^{O}$, and to corrosion of zinc, $I_{\mathrm{R}}^{\text {corr }}$.

$$
I_{\mathrm{R}}\left(I_{\mathrm{D}}=0\right)=I_{\mathrm{R}}^{\mathrm{O}}+I_{\mathrm{R}}^{\mathrm{corr}}
$$

The corrosion rate can be estimated from ring current data at the beginning of a series of experiments, viz. before disc currents were applied, but after the oxygen had been removed from the solution. In Fig. 11, these ring current data are plotted versus $\mathrm{KOH}$ concentration for various zincate concentrations. The figure shows that the amount of hydrogen increases with increasing $\mathrm{KOH}$ and decreasing zincate concentration, in agreement with the findings of Dirkse and Timmer [10] and Muralidharan and Rajagopalan [11].

Dirkse and Timmer ascribe the decrease of the corrosion rate in electrolytes saturated with $\mathrm{ZnO}$ to a

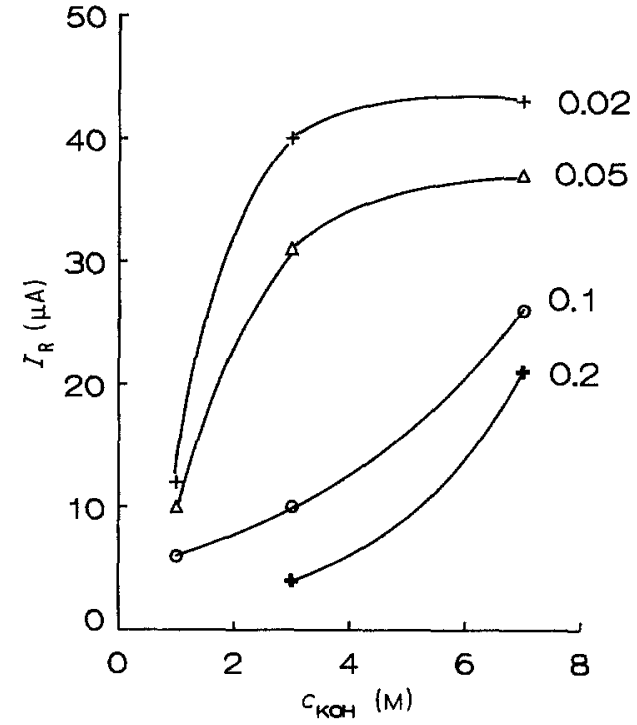

Fig. 11. Ring current at the beginning of a series of experiments, i.e. before zinc deposition experiments were performed and after the 30 -min stand in solution, as a function of $\mathrm{KOH}$ concentration for various zincate concentrations. Numbers in figure indicate $c_{\mathrm{K}_{2} \mathrm{Zn}(\mathrm{OH})_{4}}$ (M). $E_{\mathrm{R}}=-0.2 \mathrm{~V}(\mathrm{Hg} / \mathrm{HgO}), f=25 \mathrm{~s}^{-1}$.

slow dissolution of anodic reaction products. A protective layer of $\mathrm{ZnO}$ or $\mathrm{Zn}(\mathrm{OH})_{2}$ is formed at the zinc surface, a phenomenon also observed by Cachet et al. [17]. Therefore, an increasing zincate concentration results in a decrease of the zinc dissolution rate and, consequently, in a decrease of the corrosion rate.

Muralidharan and Rajagopalan [11] did not discuss the increase of the corrosion with increasing $\mathrm{KOH}$ and decreasing zincate concentration. Dirkse and Timmer [10] only discussed zinc electrode corrosion in concentrated alkaline electrolytes $(>35 \% \mathrm{KOH})$. If it is assumed that the anodic process determines the corrosion rate, it is likely that the increase of corrosion with increasing $\mathrm{KOH}$ concentration can be attributed to the increasing solubility of the protective layer of $\mathrm{ZnO}$ or $\mathrm{Zn}(\mathrm{OH})_{2}$ on the electrode surface. However, more research has to be performed to understand the processes involved in zinc electrode corrosion.

\subsection{The calculation of the hydrogen current}

The electrochemically formed hydrogen during the electrodeposition of zinc is to be determined. During cathodic polarization of the disc, the measured ring current is not only due to the oxidation of electrochemically formed hydrogen, $I_{\mathrm{R}}^{\mathrm{E}}$, but also due to the oxidation of dissolved hydrogen, $I_{\mathrm{R}}^{\mathrm{O}}\left(I_{\mathrm{D}}<0\right)$, and of hydrogen formed as a result of the chemical reaction of zinc and water, i.e. 'corrosion', $I_{\mathrm{R}}^{\text {corr }}\left(I_{\mathrm{D}}<0\right)$.

$$
I_{\mathrm{R}}=I_{\mathrm{R}}^{\mathrm{E}}+I_{\mathrm{R}}^{\mathrm{O}}\left(I_{\mathrm{D}}<0\right)+I_{\mathrm{R}}^{\text {corr }}\left(I_{\mathrm{D}}<0\right)
$$

The hydrogen current which corresponds with electrochemically formed hydrogen is equal to the ratio of $I_{\mathrm{R}}^{\mathrm{E}}$ and the collection efficiency. In this paper the hydrogen current is calculated from Equation 3, where the measured ring current is corrected with the non-zero ring current at open circuit potential of the disc, $I_{\mathrm{R}}\left(I_{\mathrm{D}}=0\right)$. Combination of Equations 3,8 and 
Table 1. Hydrogen solubility data and Levich slopes for pure $\mathrm{KOH}$ electrolytes

\begin{tabular}{rlll}
\hline $\begin{array}{c}\mathrm{c}_{\mathrm{KOH}} \\
(M)\end{array}$ & $\begin{array}{l}\mathrm{c}_{\mathrm{H}_{2}} \\
(m M)\end{array}$ & $\begin{array}{l}\mathrm{S} \\
\left(\mu A s^{-1 / 2}\right)\end{array}$ & $\begin{array}{l}\mathrm{Sc}_{\mathrm{H}_{2}}^{-1} \\
\left(m A M^{-1} s^{-1 / 2}\right)\end{array}$ \\
\hline 1 & 0.575 & 77 & 133 \\
3 & 0.315 & 40 & 126 \\
7 & 0.100 & 13 & 130 \\
10 & 0.041 & 5 & 128 \\
\hline
\end{tabular}

9 and assuming that $I_{\mathrm{R}}^{\mathrm{O}}\left(I_{\mathrm{D}}<0\right)$ is equal to $I_{\mathrm{R}}^{\mathrm{O}}$, i.e. during the period in between deposition experiments the amount of dissolved hydrogen remains constant, yields

$$
I_{\mathrm{H}_{2}}=\left(I_{\mathrm{R}}^{\mathrm{E}}+I_{\mathrm{R}}^{\mathrm{corr}}\left(I_{\mathrm{D}}<0\right)-I_{\mathrm{R}}^{\text {corr }}\right) / N
$$

At low $\mathrm{KOH}$ concentration $I_{\mathrm{R}}^{\text {corr }}$, the corrosion at open circuit potential, and $I_{\mathrm{R}}^{\text {corr }}\left(I_{\mathrm{D}}<0\right)$ are of almost no significance, whereas at high $\mathrm{KOH}$ concentration they cannot be neglected (cf. Fig. 11). But even at high $\mathrm{KOH}$ concentration and small applied disc currents, the corrosion terms in Equation 10 may cancel out. The chemical dissolution of zinc at high cathodic disc currents is expected to be negligibly small and, therefore, only at high $\mathrm{KOH}$ concentrations and high disc currents is an error introduced into the calculation of $I_{\mathrm{H}_{2}}$ using Equation 3, its value being smaller than that obtained from the ratio of $I_{\mathrm{R}}^{\mathrm{E}}$ and $N$.

\subsection{The hydrogen solubility in alkaline zincate electrolytes}

It is obvious that the hydrogen solubility sets the upper limit for which the RRDE technique can be applied. The solubility of $\mathrm{H}_{2}$ in pure $\mathrm{KOH}$ solutions can be obtained from literature data [18], from which the maximum ring current, $I_{\mathrm{R}}^{\text {sol }}$, can be calculated. However data on the solubility of $\mathrm{H}_{2}$ in alkaline zincate solutions are not tabulated in the literature. Therefore rotating disc electrode (RDE) experiments were carried out to estimate the hydrogen solubility.

The hydrogen oxidation is mass transport limited at a Pt RDE, at a potential of $-0.2 \mathrm{~V}(\mathrm{Hg} / \mathrm{HgO})$, as was shown in Fig. 2. The limiting current at the disc, $I_{1}$, can be calculated fom the Levich equation [19], which can be written as:

$$
\begin{aligned}
I_{1} & =S f^{1 / 2} \\
S & =3.83 n F A D_{\mathrm{H}_{2}}^{2 / 3} v^{-1 / 6} c_{\mathrm{H}_{2}}
\end{aligned}
$$

In these equations, $n, F$ and $A$ have their usual meaning, $D_{\mathrm{H}_{2}}$ is the diffusion coefficient of $\mathrm{H}_{2}, f$ the rotation frequency, $v$ the kinematic viscosity and $c_{\mathrm{H}_{2}}$ the concentration of hydrogen in the electrolyte. The plot of $I_{1}$ versus $f^{1 / 2}$ results in a straight line, with a slope, $S$, depending on $D_{\mathrm{H}_{2}}, c_{\mathrm{H}_{2}}$ and $v$.

The slope of the plot of $I_{1}$ versus $f^{1 / 2}$ was established for various hydrogen-saturated zincate-free alkaline electrolytes. In Fig. 12, these slopes are plotted versus $\mathrm{KOH}$ concentration. In Table 1 these results are summarized with data for the hydrogen solubility. It

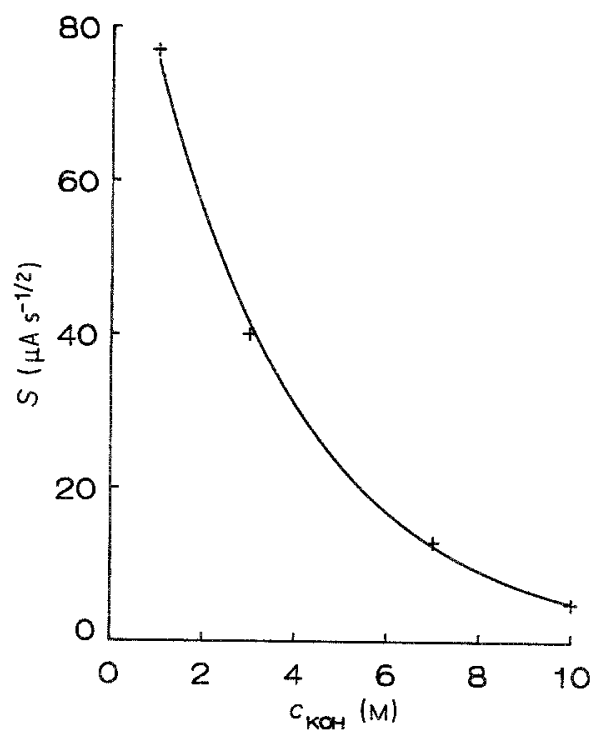

Fig. 12. The Levich slope of the hydrogen oxidation reaction at a platinum electrode versus $\mathrm{KOH}$ concentration (zincate free, hydrogen saturated). $E=-0.2 \mathrm{~V}(\mathrm{Hg} / \mathrm{HgO}), f=25 \mathrm{~s}^{-1}$.

appears that the ratio of $S$ and $c_{\mathrm{H}_{2}}$ is constant for $\mathrm{KOH}$ concentrations from 1 to $10 \mathrm{M}$. Thus, the factor $D_{\mathrm{H}_{2}}^{2 / 3} v^{-1 / 6}$ is constant over the range of $\mathrm{KOH}$ concentrations studied.

A similar procedure was followed for the determination of the hydrogen solubility in alkaline zincate electrolytes. A plot of the slope as a function of zincate concentration in $7 \mathrm{M} \mathrm{KOH}$ is depicted in Fig. 13. Assuming that the change in magnitude of the slope only depends on $c_{\mathrm{H}_{2}}$, as was the case with the pure $\mathrm{KOH}$ electrolytes, $S$ is a measure for the hydrogen solubility in alkaline zincate electrolytes and the hydrogen solubility can be calculated from these data. The results for the $7 \mathrm{M} \mathrm{KOH}$ zincate electrolytes are presented in Table 2. The maximum amount of hydrogen which can be reliably measured with the RRDE technique can be evaluated from these data. Calculated values of

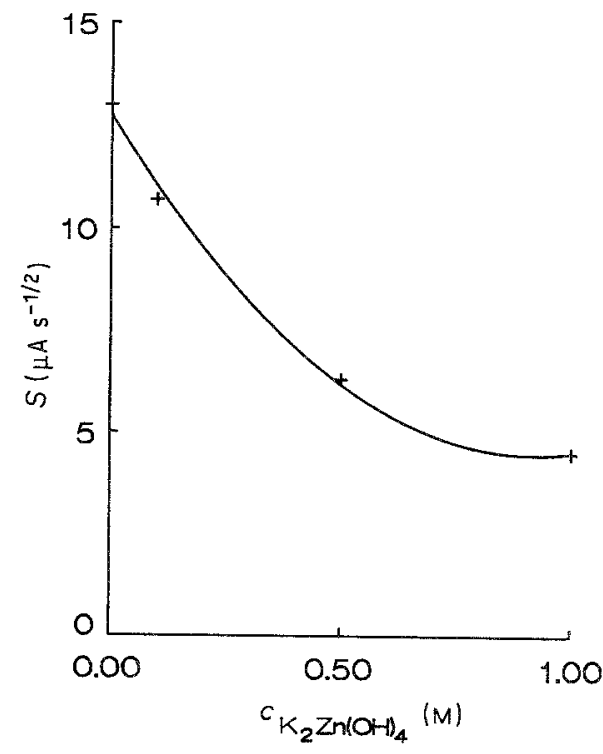

Fig. 13. The Levich slope of the hydrogen oxidation reaction in hydrogen-saturated $7 \mathrm{M} \mathrm{KOH}$ at a platinum electrode versus zincate concentration. $E=-0.2 \mathrm{~V}(\mathrm{Hg} / \mathrm{HgO}), f=25 \mathrm{~s}^{-1}$. 
Table 2. Calculated hydrogen solubility in $7 \mathrm{M} \mathrm{KOH}$ and various zincate concentrations

\begin{tabular}{lll}
\hline $\begin{array}{l}\mathrm{c}_{\mathrm{K}_{2} \mathrm{Zn}(\mathrm{OH})_{4}} \\
(M)\end{array}$ & $\begin{array}{l}\mathrm{S} \\
\left(\mu A s^{-1 / 2}\right)\end{array}$ & $\begin{array}{l}\mathrm{c}_{\mathrm{H}_{2}} \\
(m M)\end{array}$ \\
\hline 0 & 13.0 & 0.100 \\
0.1 & 10.7 & 0.08 \\
0.5 & 6.3 & 0.047 \\
1.0 & 4.5 & 0.034 \\
\hline
\end{tabular}

the maximum ring current, $I_{\mathrm{R}}^{\text {sol }}$, for various electrolyte compositions, are presented in Table 3.

$I_{\mathrm{R}}^{\text {sol }}$ concerns the total amount of dissolved $\mathrm{H}_{2}$, calculated from the hydrogen solubility. It offers a first approximation of the maximum amount of dissolved hydrogen which can be detected with the RRDE technique. However, the ring current associated with the maximum amount of $\mathrm{H}_{2}$ which can be determined during the deposition experiments, $I_{\mathrm{R}}^{\max }$, will differ from this value. This difference between $I_{\mathrm{R}}^{\text {sol }}$ and $I_{\mathrm{R}}^{\max }$ depends on experimental conditions and is mainly due to hydrogen supersaturation and to the presence of dissolved hydrogen resulting from previous deposition experiments. Therefore, $I_{\mathrm{R}}^{\max }$ cannot be evaluated a priori, and $I_{\mathrm{R}}^{\text {sol }}$ has to be used as an indication of $I_{\mathrm{R}}^{\max }$.

It is clear that the domain of hydrogen currents which can be reliably measured with the RRDE technique decreases with increasing $\mathrm{KOH}$ concentrations. The hydrogen solubility decreases (cf. Table 1) and zinc corrosion increases (see Fig. 11) with increasing $\mathrm{KOH}$ concentration. In fact, measurements in $10 \mathrm{M} \mathrm{KOH}$ failed as a result of this limited domain of hydrogen currents.

\section{Conclusion}

The RRDE technique offers an elegant and useful method for the detection of hydrogen in alkaline electrolytes, particularly in the less concentrated alkaline solutions.

The hydrogen solubility in various alkaline zincate electrolytes was estimated from Levich plots, assuming that the slope of the Levich plot depends only on hydrogen concentration in the electrolyte.

With the RRDE technique, the amount of hydrogen produced during zinc electrodeposition and zinc electrode corrosion has been determined for various alkaline zincate electrolytes. It was found that the hydrogen production increases with decreasing zincate and $\mathrm{KOH}$ concentration. The established hydrogen formation curves indicate that in battery electrolytes $(8 \mathrm{M} \mathrm{KOH}, 1 \mathrm{M}$ zincate) the electrochemical hydrogen production during electrodeposition is very small. Even at the end of the charge halfcycle, when zincate concentration will be at a minimum but $\mathrm{KOH}$ concentration at a maximum, hydrogen production will still be small. The battery charge efficiency will be lowered by at most $0.5 \%$ as a result of electrochemically formed hydrogen. However, this value depends not only on the applied current density and initial solute concen-
Table 3. Estimated maximum ring current for various electrolyte compositions, calculated from experimental Levich slopes

\begin{tabular}{lll}
\hline $\mathrm{c}_{\mathrm{KOH}}$ & $\mathrm{c}_{\mathrm{K}_{2} \mathrm{Zn}(\mathrm{OH})_{4}}$ & $\begin{array}{l}\mathrm{I}_{\mathrm{R}}^{\mathrm{sol}} \\
(M)\end{array}$ \\
\hline$(M)$ & $(\mu A)$ \\
\hline 1 & 0 & 400 \\
1 & 0.1 & 290 \\
3 & 0 & 210 \\
3 & 0.2 & 120 \\
7 & 0 & 65 \\
7 & 0.2 & 40 \\
\hline
\end{tabular}

trations but also on the kind of zinc electrode (type of binder material and additives and porosity), purity of the electrolyte and battery cell geometry (electrolyte volume and current density distribution). Hence, it is concluded that in zinc secondary batteries, hydrogen is produced mainly through zinc electrode corrosion.

The recommendation of Rogers and Taylor [8] that hydrogen formation should be allowed so as to improve stirring of the electrolyte must be contradicted. Hydrogen gas bubble formation causes a considerable increase in the local current density and an ohmic drop in the vicinity of the bubble, which is a considerable drawback with only a small gain in electrolyte stirring.

\section{Acknowledgement}

The authors wish to thank A. Cox for the careful and accurate performance of the experimental work.

\section{References}

[1] E. J. Frazer and T. Lwin, J. Appl. Electrochem. 17 (1987) 453.

[2] T. Biegler and E. J. Frazer, ibid. 16 (1986) 654

[3] E. J. Frazer and I. C. Hamilton, ibid. 16 (1986) 387.

[4] A. C. Beshore, B. F. Flori, G. Schade and T. J. O'Keefe, ibid. 17 (1987) 765.

[5] M. M. Jaksic, Surf. Coat. Tech. 29 (1986) 95.

[6] J. St Pierre and D. L. Piron, J. Appl. Electrochem. 16 (1986) 447.

[7] G. D. Wilcox and P. J. Mitchell, Trans. Inst. Met. Finish. 65 (1987) 76.

[8] G. T. Rogers and K. J. Taylor, J. Electroanal. Chem. 167 (1984) 251.

[9] R. N. Snyder and J. J. Lander, J. Electrochem. Technol. 3 (1965) 161.

[10] T. P. Dirkse and R. Timmer, J. Electrochem. Soc. 116, (1969) 162.

[11] V. S. Muralidharan and K. S. Rajagopalan, J. Electroanal. Chem. 94 (1978) 21.

[12] A. van der Putten, PhD Thesis, Eindhoven University of Technology, The Netherlands (1987) Ch. 3.

[13] W. J. Albery and S. Bruckenstein, Trans. Faraday Soc. 62 (1966) 1920.

[14] L. M. Baugh, F. L. Tye and N. L. White, 'Power Sources' No. 9 (edited by J. Thomson). Academic Press, London (1983) p. 303.

[15] Z. A. Iofa, L. V. Komlev and V. S. Bagotskii, Russ. J. Phys. Chem. 35 (1961) 770.

[16] T. S. Lee, J. Electrochem. Soc. 118 (1971) 1278.

[17] C. Cachet, B. Saidani and R. Wiart, 38th Meeting of the Int. Soc. of Electrochem., Maastricht, The Netherlands, 'Extended Abstracts', Vol. I, p. 322.

[18] Solubility Data Series, Vol 5/6, 'Hydrogen and Deuterium', (edited by C. L. Young). Pergamon Press, Oxford (1981).

[19] A. J. Bard and L. R. Faulkner, 'Electrochemical Methods', Wiley, New York (1980). 